\title{
Compatibility of Shrinkage-Reducing and Air-Entraining Admixtures
}

\author{
by Benjamin Pendergrass, David Darwin, Muzai Feng, and Rouzbeh Khajehdehi
}

The compatibility of two shrinkage-reducing admixtures (SRAs) with two air-entraining admixtures (AEAs) —one surfactant-based and one foaming polymer-based - was examined based on freezingand-thawing durability, scaling resistance, and air-void characteristics of hardened concrete. SRA dosages of 0, 0.5, 1.0, and 2.0\% by weight of cement were used. Test results show that interactions between admixtures can reduce air-void stability, contributing to lowered freezing-and-thawing durability and scaling resistance. Without an SRA, concrete mixtures containing either AEA exhibited good freezing-and-thawing durability and scaling resistance. With an SRA, mixtures containing the surfactant-based AEA performed well, while those containing the polymer-based AEA did not. Mixtures containing higher dosages of SRA, regardless of $A E A$, experienced a greater loss in air content in concrete between the plastic and hardened conditions. Mixtures with an increased air-void spacing factor experienced decreased durability, with the greatest decrease observed in those with air-void spacing factors greater than $0.008 \mathrm{in} .(0.20 \mathrm{~mm})$.

Keywords: admixtures; air-void analysis; freezing-and-thawing durability; scaling resistance; shrinkage.

\section{INTRODUCTION}

Cracking due to restrained drying shrinkage is a primary cause of deterioration and reduced service life in concrete structures, such as bridge decks, due to its effect on accelerating corrosion of reinforcing steel. Cracks allow water and deicing chemicals to penetrate the concrete and reach the reinforcement. One method used to improve the shrinkage performance of concrete is through the addition of a shrinkage-reducing admixture.

Shrinkage-reducing admixtures (SRAs) function by reducing the surface tension of water in the pores within hardened concrete, thus reducing the stresses that cause shrinkage. The reduction in surface tension occurs in plastic as well as hardened concrete. Surfactant-based air-entraining admixtures (AEAs) also reduce the surface tension of water, which promotes the formation of air bubbles during mixing (Mindess et al. 2003). When a shrinkage-reducing admixture and a surfactant-based AEA are used together, the combined effect on surface tension in plastic concrete may result in larger air voids than desired and instability of the air-void system, which can contribute to reduced freezingand-thawing performance. One justification offered for using a foaming polymer-based AEA, which requires specialized aeration equipment to generate the foam that is then dispersed throughout the concrete, is that it produces an air-void system that is less sensitive to the effects of SRAs than the air-void system produced by surfactant-based AEAs.

Bedard and Mailvaganam (2006) studied the problem of incompatibility between admixtures but did not address the interaction between shrinkage-reducing and air-entraining admixtures. Lopes et al. (2013) found that, by itself, a shrinkage-reducing admixture does not affect the durability of high-strength concrete in terms of resistance to aggressive agents, such as water and deicing chemicals.

This paper presents a study in which concretes containing either a surfactant-based or foaming polymer-based AEA in conjunction with one of two SRAs are compared based on freezing-and-thawing durability, scaling resistance, and air-void stability. The study presented in this paper is part of a long-term research program at the University of Kansas to develop low-cracking high-performance concrete (LC-HPC) for bridge deck applications (Darwin et al. 2004, 2010, 2012; Lindquist et al. 2006, 2008; McLeod et al. 2009, 2010; Pendergrass and Darwin 2014; Yuan et al. 2011, 2015).

\section{RESEARCH SIGNIFICANCE}

Recent advances in admixture technology have resulted in the increased use of shrinkage-reducing admixtures to improve the cracking performance of concrete. Concrete mixtures often contain combinations of admixtures that can lead to durability problems in hardened concrete. The current study demonstrates the impact of admixture incompatibility on the air-void system and the durability of concrete, and emphasizes the importance of checking for admixture compatibility before application in the field.

\section{EXPERIMENTAL WORK}

\section{Materials}

The concrete mixtures used in this study contained Type I/II cement complying with ASTM C150/C150M. Granite with maximum sizes of 1 and 3/4 in. (25 and $19 \mathrm{~mm}$ ) was used as coarse aggregate and river-run sand and pea gravel were used as fine aggregates.

The two SRAs used in the study, SRA-1 and SRA-2, function by minimizing the surface tension of the pore solution. One of the two AEAs used in this study, sAEA, is a tall oil-based surfactant, while the other, pAEA, is a synthetic, polymer-based foam. The mixtures also contained a polycarboxylate-based high-range water-reducing admixture (HRWRA), which was used to achieve the desired concrete slump. The SRA-1, SRA-2, sAEA, and HRWRA were produced by the same manufacturer.

ACI Materials Journal, V. 114, No. 5, September-October 2017.

MS No. M-2016-400, doi: 10.14359/51689900, was received November 11, 2016, and reviewed under Institute publication policies. Copyright (C) 2017, American Concrete Institute. All rights reserved, including the making of copies unless permission is obtained from the copyright proprietors. Pertinent discussion including author's closure, if any, will be published ten months from this journal's date if the discussion is received within four months of the paper's print publication. 
Table 1-Mixture proportions

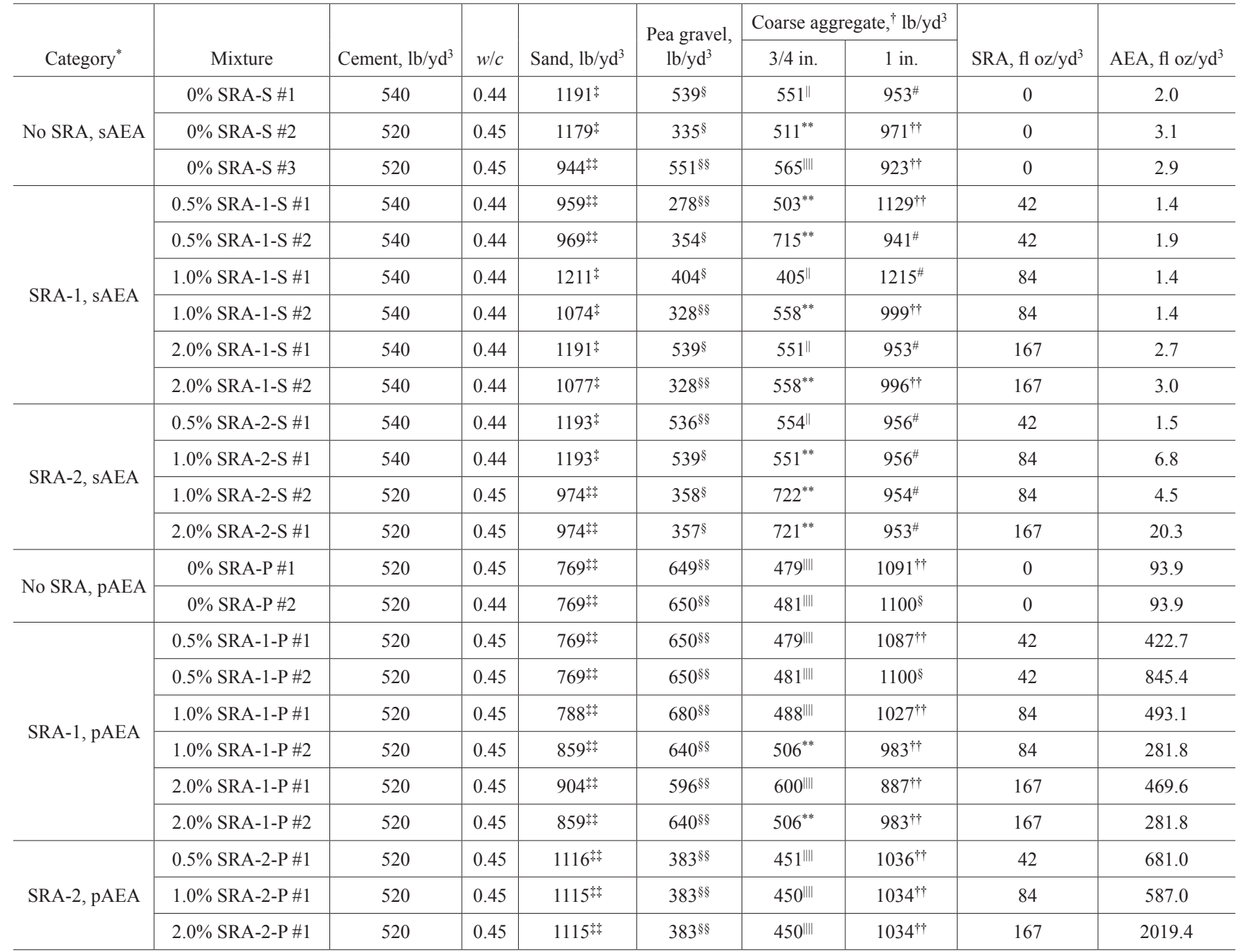

*S and $\mathrm{P}$ denote, respectively, mixtures containing surfactant-based and foaming polymer AEAs.

†3/4 in. and 1 in. denote maximum sizes of granite used in blend.

Bulk specific gravity, BSG (SSD) is 2.61 , absorption, ABS (dry) is $0.77 \%$; ${ }^{\text {tat }} \mathrm{BSG}$ (SSD) is 2.62 , ABS (dry) is $0.86 \%$; ${ }^{\S}$ Bulk specific gravity (SSD) is 2.60 , ABS (dry) is $0.70 \%$; ${ }^{\S} \mathrm{BSG}$ (SSD) is 2.59 , ABS (dry) is $0.84 \%$; ${ }^{\mathrm{BSG}}$ (SSD) is 2.62 , ABS (dry) is $0.81 \%$; ${ }^{* *} \mathrm{BSG}$ (SSD) is 2.59 ; ABS (dry) is $0.83 \%$; ${ }^{\prime \prime \prime} \mathrm{BSG}(\mathrm{SSD})$ is $2.60, \mathrm{ABS}$ (dry) is $1.05 \%$; ${ }^{\#} \mathrm{BSG}$ (SSD) is 2.61 , ABS (dry) is $0.63 \%$; ${ }^{\dagger} \mathrm{BSG}$ (SSD) is 2.59 , ABS (dry) is $0.70 \%$.

Notes: $1 \mathrm{lb} / \mathrm{yd}^{3}=0.593 \mathrm{~kg} / \mathrm{m}^{3} ; 1 \mathrm{fl} \mathrm{oz} / \mathrm{yd}^{3}=38.681 \mathrm{~mL} / \mathrm{m}^{3} ; 1$ in. $=25.4 \mathrm{~mm}$.

\section{Concrete mixtures}

The concrete mixtures used in this study were designed for potential application in low-cracking high-performance concrete bridge decks. The mixtures had relatively low paste contents, low slump, high air content, moderate watercement ratios $(w / c)$, and an optimized aggregate gradation.

Twenty-four batches of concrete containing dosages of $0,0.5,1.0$, and $2.0 \%$ by weight of cement of SRA- 1 or SRA-2 were examined. The mixture proportions are shown in Table 1. The mixture designations are based on the percentage of SRA by weight of cement $(0,0.5,1.0$, and $2.0 \%$ ), SRA type (SRA-1 or SRA-2), and whether sAEA (designated by "S") or pAEA (designated by "P") were used. Of the 24 batches, 10 were replicates, which are identified with a \#2 or \#3. Cement contents of 520 and $540 \mathrm{lb} / \mathrm{yd}^{3}$ (308 and $320 \mathrm{~kg} / \mathrm{m}^{3}$ ) were used. Mixtures containing $520 \mathrm{lb} / \mathrm{yd}^{3}$ $\left(308 \mathrm{~kg} / \mathrm{m}^{3}\right)$ of cement were proportioned using a $w / c$ of 0.45 , except for one mixture containing pAEA and no SRA (designated as $0 \%$ SRA-P \#2), which had a $w / c$ of 0.44 . The mixtures containing $540 \mathrm{lb} / \mathrm{yd}^{3}\left(320 \mathrm{~kg} / \mathrm{m}^{3}\right)$ of cement were proportioned using a $w / c$ of 0.44 . The cement paste contents ranged from 23.7 to $24.3 \%$ of the concrete volume, except for one batch with a $23.4 \%$ paste content ( $0 \%$ SRA-P \#2).

Batching temperature, slump, plastic air content, and compressive strength at 28 days are given in Table 2 . Concrete slumps ranged from $1-3 / 4$ to 5 in. (45 to $125 \mathrm{~mm}$ ), while plastic air contents ranged from 7.5 to $9.5 \%$. Batching temperatures ranged from 65 to $76^{\circ} \mathrm{F}\left(18\right.$ to $\left.24^{\circ} \mathrm{C}\right)$, and 28-day compressive strengths ranged from 3390 to $5270 \mathrm{psi}$ (23.4 to $36.4 \mathrm{MPa}$ ).

\section{Freezing-and-thawing durability and fundamental transverse frequency}

Freezing-and-thawing durability and fundamental transverse frequency tests were performed in accordance with Procedure B of ASTM C666/C666M and ASTM C215, respectively. Three $16 \times 3 \times 4$ in. (406 × 76 × $102 \mathrm{~mm})$ specimens were prepared for each batch in accordance with 
Table 2-Concrete mixture properties

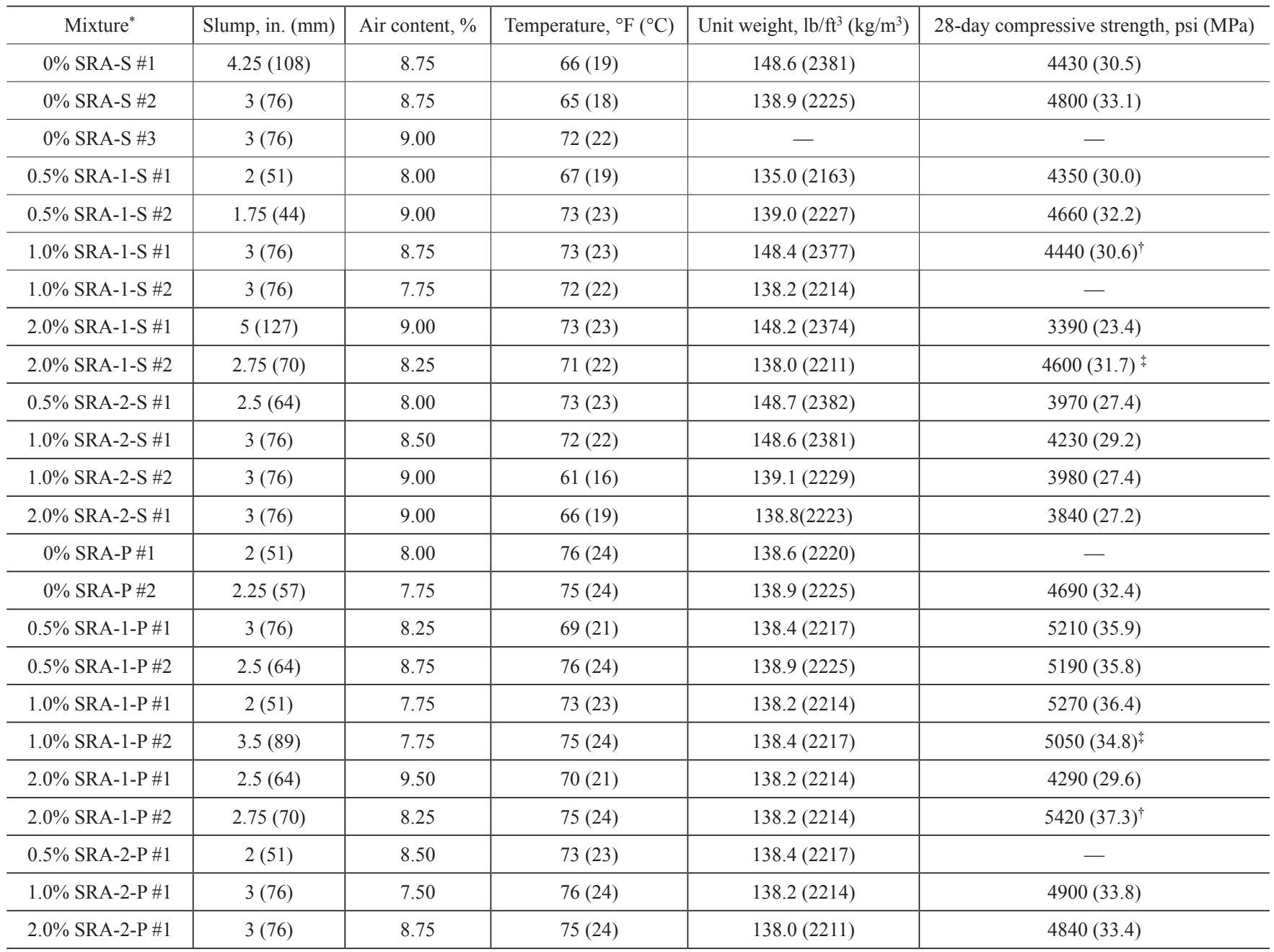

Note: "—" is data not obtained.

${ }^{*} \mathrm{~S}$ and $\mathrm{P}$ denote, respectively, mixtures containing surfactant-based and foaming polymer air-entertaining agents; ${ }^{\dagger} 37$-day cylinder strength; ${ }^{\star 33}$-day cylinder strength

ASTM C192/C192M. Steel molds were used for dimensional consistency.

The specimens were subjected to 3-hour freezing-andthawing cycles using an automated 20-block concrete freezing-and-thawing machine. The temperature was alternately lowered from 40 to $0^{\circ} \mathrm{F}\left(4\right.$ to $\left.-18^{\circ} \mathrm{C}\right)$ in air and raised from 0 to $40^{\circ} \mathrm{F}\left(-18\right.$ to $\left.4^{\circ} \mathrm{C}\right)$ in water for a single freezingand-thawing cycle. The specimens were removed from the machine in the thawed condition at intervals, typically after 30 to 35 cycles but ranging from four to 48 cycles, for the determination of mass and the fundamental transverse frequency. Testing continued until specimens were subjected to at least 300 freezing-and-thawing cycles or until the average dynamic modulus of elasticity of the specimens dropped below $60 \%$ of the initial dynamic modulus.

To determine the dynamic modulus of elasticity, specimens were dried to a surface-dry condition and weighed after removal from the freezing-and-thawing machine. The specimens were immediately placed in an enclosed storage cooler to prevent further moisture loss. The fundamental transverse frequency of each specimen was then determined in accordance with ASTM C215-the impact resonance method. The dynamic modulus of elasticity was determined for each specimen using Eq. (1), which is based on the transverse frequency and the specimen mass in accordance with ASTM C215.

$$
\text { Dyn. } E=C \cdot M \cdot n^{2}
$$

where Dyn. $E$ is the dynamic modulus of elasticity $(\mathrm{Pa}) ; C=$ $1083.6 \mathrm{~m}^{-1}$ (this constant is based on specimen shape and Poisson's ratio as provided in ASTM C215); $M$ is specimen mass (kg); and $n$ is fundamental transverse frequency $(\mathrm{Hz})$.

The freezing-and-thawing performance of the mixtures was evaluated based on the percentage of the dynamic modulus of elasticity remaining at the test completion. In accordance with ASTM C666/C666M, the freezing-andthawing performance was quantified by a durability factor $(D F)$, determined for each mixture using Eq. (2).

$$
D F=\frac{P \cdot N}{M}
$$

where $P$ is the percentage of initial dynamic modulus of elasticity remaining at $N$ cycles; $N$ is the number of cycles at which $P$ reached $60 \%$ or 300 cycles (whichever is less); and $M=300$ cycles. 


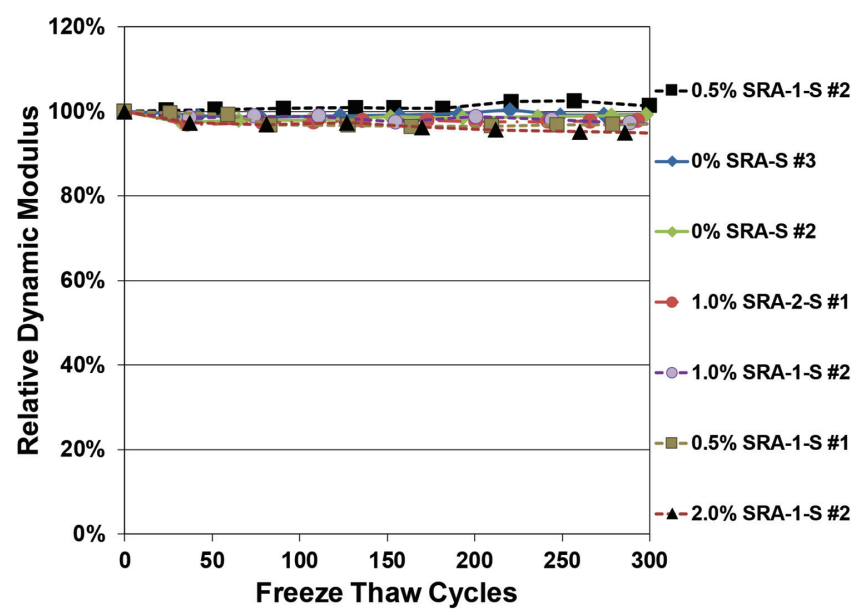

Fig. 1-Average relative dynamic modulus of elasticity versus freezing-and-thawing cycles for mixtures containing surfactant-based air-entraining agent sAEA.

\section{Scaling resistance}

Scaling resistance tests were performed in accordance with Canadian Test BNQ NQ 2621-900 Annex B, with minor modifications, including different freezing-andthawing cycle temperatures, a lower $\mathrm{NaCl}$ solution concentration, and a smaller screen size to determine mass loss. The Canadian Test was used in place of ASTM C672/ C672M based on observations by Bickley et al. (2006) that the Canadian Test provides a better correlation with field performance than ASTM C672/C672M. Three $9 \times 16 \times 3$ in. (229 x $406 \times 76 \mathrm{~mm})$ specimens were cast in accordance with ASTM C192/C192M using steel molds.

The specimens were demolded $23-1 / 2 \pm 1 / 2$ hours after casting, labeled, and immediately placed in lime-saturated water to cure in accordance with ASTM C511 for 13 days (14 total curing days from the casting date). After curing, the specimens were placed in an environmentally controlled room with a relative humidity of $50 \% \pm 4 \%$ and a temperature of $73^{\circ} \pm 3^{\circ} \mathrm{F}\left(23^{\circ} \pm 2^{\circ} \mathrm{C}\right)$ for 14 days (days 15 to 28 after casting). Twenty-one days after casting, a foam dike was attached to the finished surface of the specimen using a polyurethane sealant. Twenty-eight days after casting, a 1/4 in. $(6 \mathrm{~mm})$ deep layer of $2.5 \% \mathrm{NaCl}$ solution was placed within the dike of each specimen for a 7-day period at room temperature. The $2.5 \% \mathrm{NaCl}$ solution was selected in place of the BNQ NQ 2621-900 Annex B specified value of $3.0 \%$ based on work by Verbeck and Klieger (1957), who measured the effect on scaling of $\mathrm{NaCl}$ solutions with concentrations of $0,2,4,8$, and $16 \%$. They observed that maximum scaling occurred for specimens exposed to the $2 \%$ solution, followed by $4 \%$ solution. Based on the sharpness of the rise and fall of the curve fitting the data, however, a solution with a concentration just above $2 \%$ appeared to be more detrimental than one midway between 2 and $4 \%$.

Beginning 35 days after casting, the specimens were subjected to freezing-and-thawing cycles consisting of a $16 \pm 1$ hour freezing phase at $0^{\circ} \pm 5^{\circ} \mathrm{F}\left(-18^{\circ} \pm 3^{\circ} \mathrm{C}\right)$ followed by an $8 \pm 1$ hour thawing phase at $73^{\circ} \pm 3^{\circ} \mathrm{F}\left(23^{\circ} \pm 2^{\circ} \mathrm{C}\right)$. The freezing phase was performed each night in a walk-in freezer. The thawing phase was performed each day in the environ-

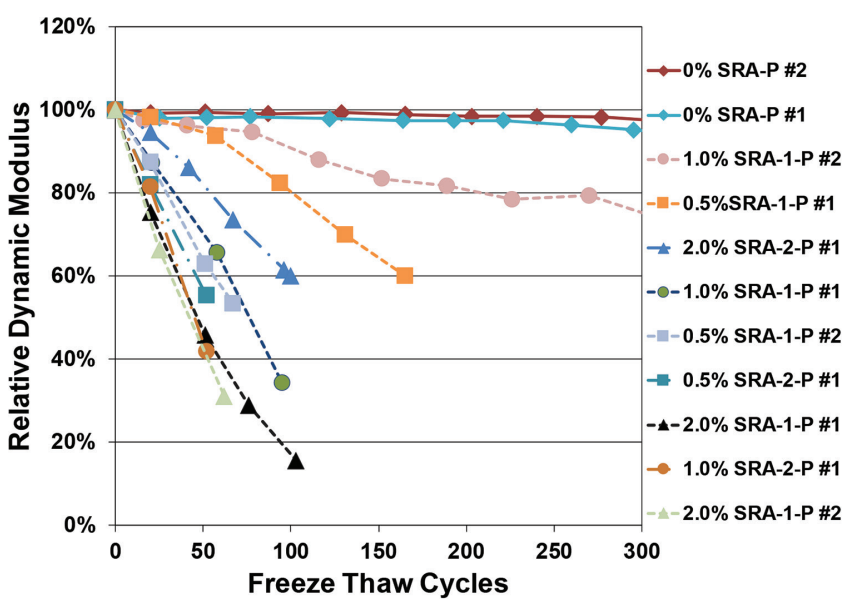

Fig. 2-Average relative dynamic modulus of elasticity versus freezing-and-thawing cycles for mixtures containing foaming polymer-based air-entraining agent $p A E A$.

mentally controlled room used after curing. The specimens remained frozen over weekends. The temperatures used in the testing (described previously) vary slightly from those specified by BNQ NQ 2621-900 Annex B, which requires $\mathrm{a}-0.4^{\circ} \pm 5.4^{\circ} \mathrm{F}\left(-18^{\circ} \pm 3^{\circ} \mathrm{C}\right)$ freezing phase followed by a $77^{\circ} \pm 5.4^{\circ} \mathrm{F}\left(25^{\circ} \pm 3^{\circ} \mathrm{C}\right)$ thawing phase. To determine the mass loss of the specimens after 7, 21, 35, and 56 cycles, the loose material produced by scaling of the top surface of the specimen was wet-sieved over a No. $200(75 \mu \mathrm{m})$ sieve instead of the BNQ NQ 2621-900 specified $80 \mu \mathrm{m}$ sieve. BNQ NQ 2621-900 allows a maximum average cumulative mass loss limit of $0.20 \mathrm{lb} / \mathrm{ft}^{2}\left(1000 \mathrm{~g} / \mathrm{m}^{2}\right)$ at test completion.

\section{Hardened concrete air-void analysis}

A hardened concrete air-void analysis was completed on cylindrical specimens in accordance with ASTM C457/ C457M, Procedure A - Linear Traverse Method. Two $4 \mathrm{x}$ 8 in. $(102 \times 203 \mathrm{~mm})$ cylindrical specimens were prepared for each batch of concrete in accordance with ASTM C192/ C192M and ASTM C31/C31M. The specimens were cast in steel molds.

The specimens were demolded $23-1 / 2 \pm 1 / 2$ hour after casting, labeled, and immediately placed in an environmentally controlled, moist-curing room with a minimum relative humidity of $95 \%$ and a temperature of $73^{\circ} \pm 3^{\circ} \mathrm{F}\left(23^{\circ} \pm 2^{\circ} \mathrm{C}\right)$ for a minimum of 14 days.

\section{RESULTS AND DISCUSSION Freezing-and-thawing durability}

The evaluation of freezing-and-thawing durability included 18 batches of concrete to examine the effects of dosage and type of SRA, and type of AEA on freezing-andthawing durability. The batches included 12 distinct mixtures, of which six were duplicated. The 18 batches included seven containing the surfactant-based air-entraining admixture sAEA and 11 containing the foaming polymer-based airentraining admixture pAEA. Four dosages of SRA- $1(0,0.5$, 1.0 , and $2.0 \%$ by weight of cement) were used in conjunction with sAEA or pAEA. In addition, one dosage of SRA-2 ( $1.0 \%$ by weight of cement) was used in mixtures containing sAEA, and three SRA-2 dosages $(0.5,1.0$, and $2.0 \%$ by 


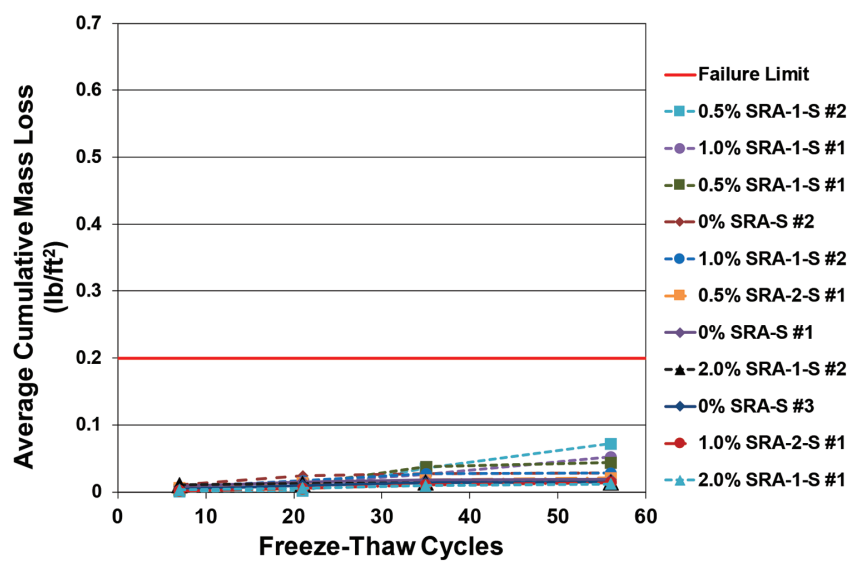

Fig. 3-Average cumulative mass loss due to scaling versus freezing-and-thawing cycles for mixtures containing surfactant-based air-entraining agent sAEA. (Note: $1 \mathrm{lb} / \mathrm{ft}^{2}=$ $4.88 \mathrm{~kg} / \mathrm{m}^{2}$ )

weight of cement) were used in mixtures containing pAEA. Duplicate batches with SRA-1 dosages of 0 and $0.5 \%$ and SAEA and SRA-1 dosages of $0,0.5,1.0$, and $2.0 \%$ and pAEA were tested.

The average relative dynamic modulus of elasticity for the three specimens from each batch, equal to the ratio of the dynamic modulus of elasticity after a given number of cycles to the dynamic modulus of elasticity prior to testing, is plotted as a function of the number of freezing-and-thawing cycles in Fig. 1 and 2, respectively, for the sAEA and pAEA mixtures. In the figure legends, the mixtures are listed in the order of descending durability factor (DF) (Eq. (2)). Table 3 shows the DFs of the mixtures and, where applicable, the number of freezing-and-thawing cycles completed prior to reaching $60 \%$ of the initial dynamic modulus. Linear interpolation between dynamic modulus and freezing-andthawing cycle was used to determine the number of freezing-and-thawing cycles corresponding to $60 \%$ of the initial dynamic modulus for the specimens that did not reach 300 cycles, and the average dynamic modulus at 300 cycles for the specimens that extended beyond 300 cycles.

The freezing-and-thawing test results in Fig. 1 and 2 and Table 3 indicate that the mixtures containing the foaming polymer-based air-entraining admixture pAEA exhibited a greater decrease in dynamic modulus of elasticity than the mixtures containing the surfactant-based air-entraining admixture sAEA for the mixtures containing a shrinkagereducing admixture. All seven mixtures containing sAEA had a DF of 95 or greater at 300 cycles. The lowest DF for the sAEA mixtures (95) was experienced by Mixture $2.0 \%$ SRA-1-S \#2. In contrast, only two of the 11 mixtures containing pAEA, neither of which contained an SRA $(0 \%$ SRA-P \#1 and 0\% SRA-P \#2), had a DF of 95 or greater at 300 cycles. These two mixtures had DFs of 95 and 98, respectively. Only one mixture containing pAEA and an SRA (1.0\% SRA-1-P \#2) reached 300 cycles before dropping below $60 \%$ of the initial dynamic modulus; this mixture had a DF of 75 at 300 cycles.

The addition of an SRA to the mixtures containing SAEA had little effect on freezing-and-thawing durability, although the mixture with an SRA-1 dosage of 2.0 percent by weight

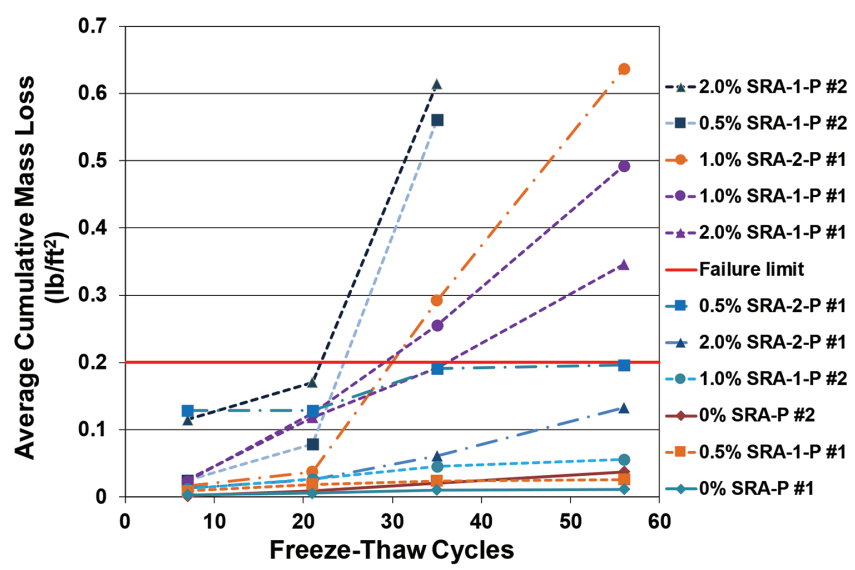

Fig. 4-Average cumulative mass loss due to scaling versus freezing-and-thawing cycles for mixtures containing foaming polymer-based air-entraining agent pAEA. (Note: $1 \mathrm{lb} / \mathrm{ft}^{2}=4.88 \mathrm{~kg} / \mathrm{m}^{2}$.)

Table 3-Average dynamic modulus of elasticity versus freezing-and-thawing cycles

\begin{tabular}{c|c|c}
\hline Mixture & $\begin{array}{c}\text { Durability } \\
\text { factor, } \%\end{array}$ & $\begin{array}{c}\text { Cycles completed at 60\% of initial } \\
\text { dynamic modulus }\end{array}$ \\
\hline $0 \%$ SRA-S \#2 & 99 & - \\
\hline $0 \%$ SRA-S \#3 & 99 & - \\
\hline $0.5 \%$ SRA-1-S \#1 & 97 & - \\
\hline $0.5 \%$ SRA-1-S \#2 & 101 & - \\
\hline $1.0 \%$ SRA-1-S \#2 & 97 & - \\
\hline $2.0 \%$ SRA-1-S \#2 & 95 & - \\
\hline $1.0 \%$ SRA-2-S \#1 & 98 & 165 \\
\hline $0 \%$ SRA-P \#1 & 95 & 56 \\
\hline $0 \%$ SRA-P \#2 & 98 & 65 \\
\hline $0.5 \%$ SRA-1-P \#1 & 33 & - \\
\hline $0.5 \%$ SRA-1-P \#2 & 11 & 36 \\
\hline $1.0 \%$ SRA-1-P \#1 & 13 & 32 \\
\hline $1.0 \%$ SRA-1-P \#2 & 75 & 46 \\
\hline $2.0 \%$ SRA-1-P \#1 & 7 & - \\
\hline $2.0 \%$ SRA-1-P \#2 & 6 & - \\
\hline $0.5 \%$ SRA-2-P \#1 & 9 & - \\
\hline $1.0 \%$ SRA-2-P \#1 & 7 & - \\
\hline $2.0 \%$ SRA-2-P \#1 & 20 & - \\
\hline
\end{tabular}

Notes: $\mathrm{S}$ and $\mathrm{P}$ denote, respectively, mixtures containing surfactant-based and foaming polymer AEAs; " -" denotes mixture reached 300 cycles.

of cement (2.0\% SRA-1-S\#2) had the lowest DF (95) among the sAEA mixtures. The mixtures containing pAEA exhibited decreased freezing-and-thawing durability as the SRA-1 dosage increased from 0 to $0.5 \%$ and again from 1.0 to $2.0 \%$. The effect on freezing-and-thawing durability of increasing dosage of SRA-2 was not clear in the mixtures containing pAEA. For example, pAEA mixtures containing SRA-2 dosages of 0.5 and $1.0 \%$ exhibited lower DFs than a pAEA mixture with a $2.0 \%$ dosage of SRA-2. The single mixture tested containing sAEA and SRA-2 $(1.0 \%$ SRA-2-S) had a DF of 98 . Mixtures with a $2.0 \%$ dosage of 
Table 4-Average cumulative mass loss due to scaling versus freezing-and-thawing cycles for mixtures

\begin{tabular}{c|c|c|c|c}
\hline \multirow{2}{*}{ Mixture } & \multicolumn{4}{|c}{ Cumulative mass loss, lb/ft } \\
\cline { 2 - 5 } & 7 cycles & 21 cycles & 35 cycles & 56 cycles \\
\hline $0 \%$ SRA-S \#1 & 0.008 & 0.015 & 0.018 & 0.019 \\
\hline $0 \%$ SRA-S \#2 & 0.011 & 0.024 & 0.028 & 0.028 \\
\hline $0 \%$ SRA-S \#3 & 0.004 & 0.010 & 0.013 & 0.014 \\
\hline $0.5 \%$ SRA-1-S \#1 & 0.003 & 0.012 & 0.038 & 0.044 \\
\hline $0.5 \%$ SRA-1-S \#2 & 0.001 & 0.002 & 0.036 & 0.072 \\
\hline $1.0 \%$ SRA-1-S \#1 & 0.003 & 0.013 & 0.026 & 0.052 \\
\hline $1.0 \%$ SRA-1-S \#2 & 0.008 & 0.016 & 0.027 & 0.028 \\
\hline $2.0 \%$ SRA-1-S \#1 & 0.003 & 0.006 & 0.009 & 0.012 \\
\hline $2.0 \%$ SRA-1-S \#2 & 0.010 & 0.012 & 0.014 & 0.015 \\
\hline $0.5 \%$ SRA-2-S \#1 & 0.006 & 0.013 & 0.018 & 0.021 \\
\hline $1.0 \%$ SRA-2-S \#1 & 0.002 & 0.005 & 0.011 & 0.014 \\
\hline $0 \%$ SRA-P \#1 & 0.003 & 0.006 & 0.010 & 0.011 \\
\hline $0 \%$ SRA-P \#2 & 0.002 & 0.010 & 0.021 & 0.038 \\
\hline $0.5 \%$ SRA-1-P \#1 & 0.009 & 0.019 & 0.024 & 0.026 \\
\hline $0.5 \%$ SRA-1-P \#2 & 0.025 & 0.079 & 0.561 & 0.577 \\
\hline $1.0 \%$ SRA-1-P \#1 & 0.023 & 0.124 & 0.255 & 0.493 \\
\hline $1.0 \%$ SRA-1-P \#2 & 0.012 & 0.027 & 0.046 & 0.056 \\
\hline $2.0 \%$ SRA-1-P \#1 & 0.056 & 0.118 & 0.182 & 0.346 \\
\hline $2.0 \%$ SRA-1-P \#2 & 0.115 & 0.170 & 0.615 & $*$ \\
\hline $0.5 \%$ SRA-2-P \#1 & 0.129 & - & 0.191 & 0.196 \\
\hline $1.0 \%$ SRA-2-P \#1 & 0.016 & 0.038 & 0.292 & 0.637 \\
\hline $2.0 \%$ SRA-2-P \#1 & 0.013 & 0.026 & 0.061 & 0.133 \\
\hline \hline
\end{tabular}

"Test terminated because cumulative mass loss was above failure limit of $0.2 \mathrm{lb} / \mathrm{ft}^{2}$. Notes: $\mathrm{S}$ and $\mathrm{P}$ denote, respectively, mixtures containing surfactant-based and foaming polymer AEAs; " - " is data not obtained; $1 \mathrm{lb} / \mathrm{ft}^{2}=4.88 \mathrm{~kg} / \mathrm{m}^{2}$.

SRA had the lowest DFs of the mixtures containing either sAEA or pAEA; however, these values were significantly lower for the pAEA mixtures. The two pAEA mixtures with the lowest DFs (2.0\% SRA-1-P \#1 and 2.0\% SRA-1-P \#2) dropped to $60 \%$ of the initial dynamic modulus of elasticity after only 36 and 32 freezing-and-thawing cycles, respectively, corresponding to DFs of 7 and 6 . An increased dosage of SRA would be expected to reduce freezing-and-thawing durability due to the effect of reduced surface tension in the plastic concrete on the air-void size. This was, however, not particularly apparent for the sAEA mixtures, all of which had a DF of at least 95 . Due to the narrow range of the values (ranging from 95 to 101), the order of descending DFs for these mixtures containing sAEA has little or no significance.

\section{Scaling resistance}

The evaluation of scaling resistance included 22 batches of concrete that included 13 distinct mixtures plus nine duplicates. As with the evaluation of freezing-and-thawing durability, the effects of dosage and type of SRA and type of AEA on scaling resistance were examined. The 22 batches included 11 each containing sAEA and pAEA. Three batches contained SAEA but no SRA and two batches contained pAEA but no SRA. Batches containing two dosages of SRA-2 ( 0.5 and $1.0 \%$ by weight of cement) were tested with the sAEA mixtures, while batches containing three SRA-2 dosages $(0.5,1.0$, and $2.0 \%$ by weight of cement) were tested with the pAEA mixtures. Duplicate batches containing three dosages of SRA-1 $(0.5,1.0$, and $2.0 \%$ by weight of cement $)$ were tested in conjunction with both sAEA and pAEA.

The average cumulative mass loss for the three specimens from each batch is plotted as a function of freezingand-thawing cycles in Fig. 3 and 4 for the sAEA and pAEA mixtures, respectively. In the figure legends, the mixtures are listed in the order of descending cumulative mass loss after 56 freezing-and-thawing cycles. Mixtures that did not reach 56 cycles are listed in the order of ascending number of freezing-and-thawing cycles to failure. Table 4 summarizes the average cumulative mass losses for the mixtures at $7,21,35$, and 56 cycles.

As shown in Fig. 3 and 4 and Table 4, the mixtures containing pAEA exhibited greater scaling losses than the mixtures containing sAEA. All mixtures containing sAEA had a cumulative mass loss below the specified failure limit $\left(0.20 \mathrm{lb} / \mathrm{ft}^{2}\left[1000 \mathrm{~g} / \mathrm{m}^{2}\right]\right)$ after 56 cycles; the maximum value was $0.072 \mathrm{lb} / \mathrm{ft}^{2}\left(360 \mathrm{~g} / \mathrm{m}^{2}\right)$. In contrast, only six of the 11 mixtures containing pAEA, including the two mixtures with no SRA, had a cumulative mass loss below the failure limit after 56 cycles. Because the sAEA and pAEA mixtures containing no SRA performed similarly, as was the case for freezing-and-thawing resistance, the tests demonstrate that mixtures containing pAEA are affected more, not less, by an SRA than the mixtures containing sAEA. Two mixtures containing pAEA and an SRA $(2.0 \%$ SRA-P \#2 and $0.5 \%$ SRA-P \#2) exceeded the specified failure limit for mass loss after only 35 cycles.

For the sAEA and pAEA mixtures containing an SRA, no clear trend can be established between dosage and scaling resistance, although an increased dosage of shrinkagereducing admixture would be expected to decrease scaling resistance due to the effect of the reduced surface tension on the air-void system. Two mixtures with a $0.5 \%$ dosage of SRA- 1 by weight of cement exhibited the second lowest $(0.5 \%$ SRA-1-P \#1) and second highest (0.5\% SRA-1-P \#2) scaling mass loss of the pAEA mixtures. For the sAEA mixtures, a mixture containing a $2.0 \%$ dosage of SRA-1 (2.0\% SRA-1-S) exhibited the lowest scaling loss, while a mixture with a dosage of $0.5 \%$ SRA-1 (0.5\% SRA-1-S \#2) exhibited the highest scaling loss; the mass losses of the sAEA mixtures, however, are all very low (below 0.012 to $0.072 \mathrm{lb} / \mathrm{ft}^{2}$ [58 to $\left.350 \mathrm{~g} / \mathrm{m}^{2}\right]$ ), and the order of decreasing cumulative mass loss for the sAEA mixtures is likely of little significance.

The results indicate that for the mixtures tested in the study, all of which had a plastic air content of at least $7.5 \%$, the addition of an SRA decreased the freezing-and-thawing durability and scaling resistance of mixtures containing pAEA, possibly due to the effect of reduced surface tension within the foam. In contrast, the addition of an SRA did not have a significant effect on the freezing-and-thawing durability or scaling resistance of mixtures containing sAEA. 

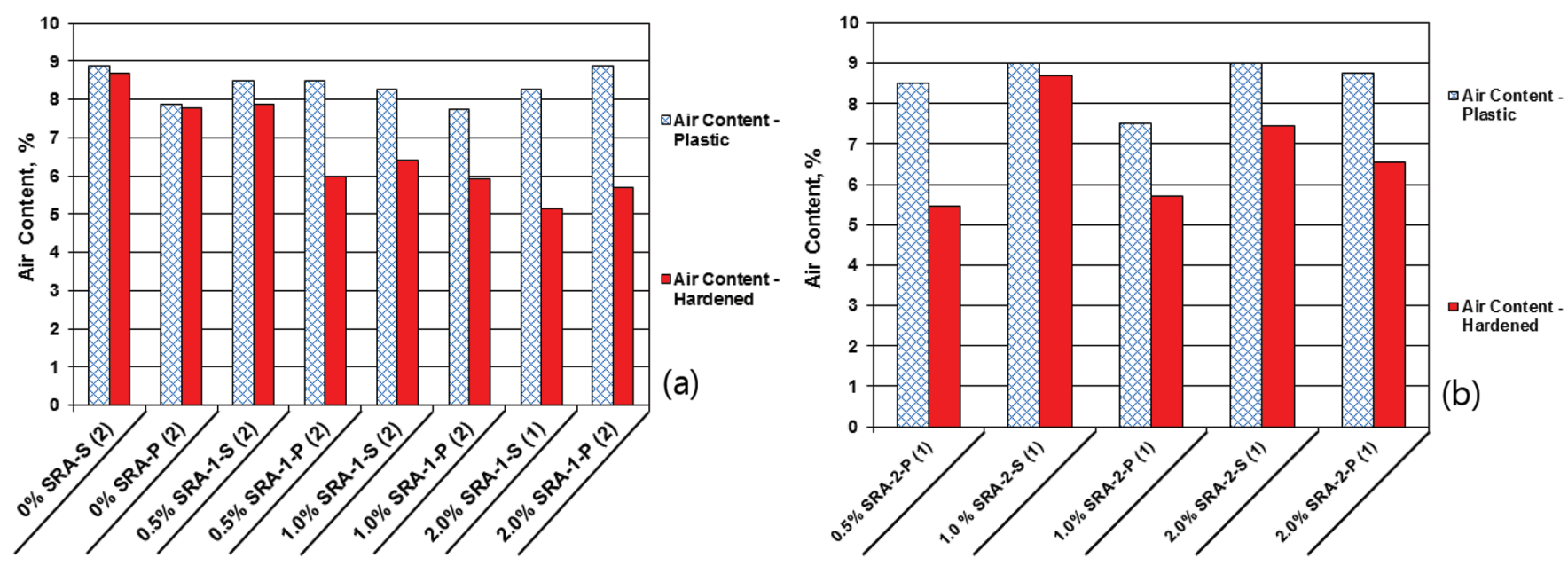

Fig. 5-(a) Air content in plastic and hardened concrete for mixtures in this study. Number of mixtures used to calculate average air contents shown in parentheses; and (b) air content in plastic and hardened concrete for mixtures containing SRA-2. Number of mixtures used to calculate average air contents shown in parentheses.

Table 5-Air contents for plastic and hardened concrete and air-void spacing for hardened concrete

\begin{tabular}{c|c|c|c|c}
\hline \multirow{2}{*}{ Mixture $^{*}$} & \multicolumn{3}{|c|}{ Average air content } & \multirow{2}{*}{$\begin{array}{c}\text { Average air-void spacing factor, } \\
\text { in. (mm) }\end{array}$} \\
\cline { 2 - 5 } $0 \%$ SRA-S (2) & Plastic, $\%$ & Hardened, $\%$ & Relative change $^{\dagger}$ & $-2.3 \%$ \\
\hline $0 \%$ SRA-P (2) & 8.9 & 8.7 & $-1.3 \%$ & $0.0037(0.09)$ \\
\hline $0.5 \%$ SRA-1-S (2) & 7.9 & 7.8 & $-7.4 \%$ & $0.0051(0.13)$ \\
\hline $0.5 \%$ SRA-1-P (2) & 8.5 & 7.9 & $-29.4 \%$ & $0.0039(0.10)$ \\
\hline $1.0 \%$ SRA-1-S (2) & 8.5 & 6.0 & $-22.1 \%$ & $0.0078(0.20)$ \\
\hline $1.0 \%$ SRA-1-P (2) & 7.8 & 6.4 & $-23.5 \%$ & $0.0052(0.13)$ \\
\hline $2.0 \%$ SRA-1-S (1) & 8.3 & 5.9 & $-37.6 \%$ & $0.0077(0.20)$ \\
\hline $2.0 \%$ SRA-1-P (2) & 8.9 & 5.2 & $-35.8 \%$ & $0.0082(0.21)$ \\
\hline $0.5 \%$ SRA-2-P (1) & 8.5 & 5.7 & $-35.9 \%$ & $0.0095(0.24)$ \\
\hline $1.0 \%$ SRA-2-S (1) & 9.0 & 5.45 & $-3.3 \%$ & $0.0091(0.23)$ \\
\hline $1.0 \%$ SRA-2-P (1) & 7.5 & 8.7 & $-24.0 \%$ & $0.0032(0.08)$ \\
\hline $2.0 \%$ SRA-2-S (1) & 9.0 & 5.7 & $-17.2 \%$ & $0.0083(0.21)$ \\
\hline $2.0 \%$ SRA-2-P (1) & 8.75 & 7.5 & $-25.1 \%$ & $0.0037(0.09)$ \\
\hline
\end{tabular}

${ }^{*} \mathrm{~S}$ and $\mathrm{P}$ denote, respectively, mixtures containing surfactant-based and foaming polymer air-entertaining agents.

${ }^{\dagger}$ Percentage difference in air content between values measured in plastic and hardened concrete.

${ }^{ \pm}$Number of batches used to calculate average air contents shown in parentheses; two specimens tested per batch.

\section{Hardened concrete air-void analysis}

The quantity and spacing of entrained air voids in concrete greatly influence the effectiveness of the air-void system in protecting concrete from freezing-and-thawing damage. The spacing of the air voids is represented by an air-void spacing factor, defined as the average distance from any point in the cement paste to the edge of the nearest void. Powers and Helmuth (1953) suggested that the air-void spacing contributes more to frost protection than actual air content. An air-void spacing factor no greater than $0.008 \mathrm{in} .(0.20 \mathrm{~mm})$ is suggested to provide sufficient freezing-and-thawing protection to concrete (Mindess et al. 2003). In addition, the volume of air recommended by ACI Committee 201 (2008) to achieve satisfactory frost protection is between $4-1 / 2$ and $6 \%$ for mixtures with a maximum aggregate size of $1 \mathrm{in}$. $(25 \mathrm{~mm})$. Specimens from 11 mixtures containing SRA-1, five mixtures containing SRA-2, and four mixtures with no SRA were tested for air-void properties in hardened concrete.

The air-void analysis results of mixtures without and with an SRA are shown in Table 5 and Fig. 5(a) and (b). Both the sAEA and pAEA mixtures with no SRA exhibited only slight reductions in air content between plastic and hardened concrete; the sAEA mixtures with no SRA ( $0 \%$ SRA-S) experienced a decrease in air content from 8.9 to $8.7 \%$ (a relative decrease of 2.3\%), while the pAEA mixtures with no SRA ( $0 \%$ SRA-P) experienced a similar decrease from 7.9 to $7.8 \%$ (a relative decrease of $1.3 \%$ ). In contrast, the sAEA and pAEA mixtures containing an SRA generally experienced progressively greater reductions in air content between plastic and hardened concrete with an increased dosage of SRA, suggesting that the decreased surface tension of the water caused by the SRA reduced the stability 


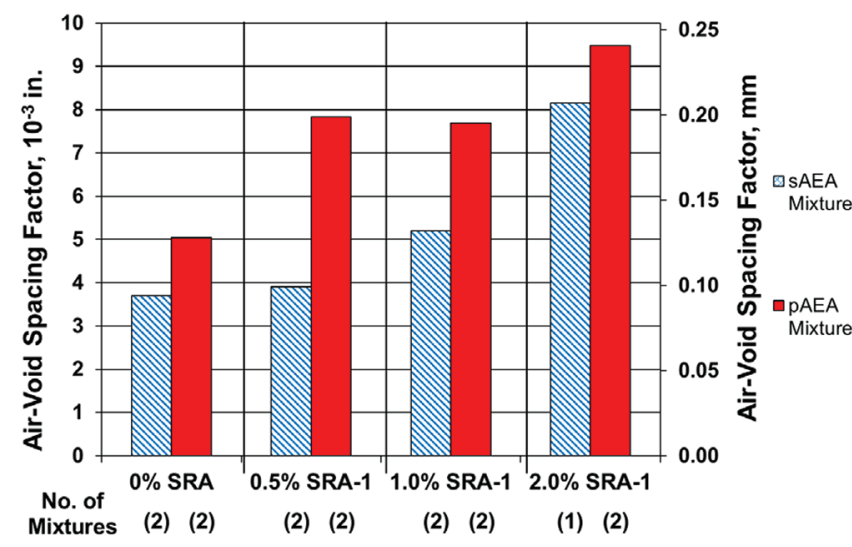

Fig. 6-Average air-void spacing factor for $S A E A$ and $p A E A$ mixtures with different dosages of $S R A-1(0,0.5,1.0$, and 2.0\% by weight of cement).

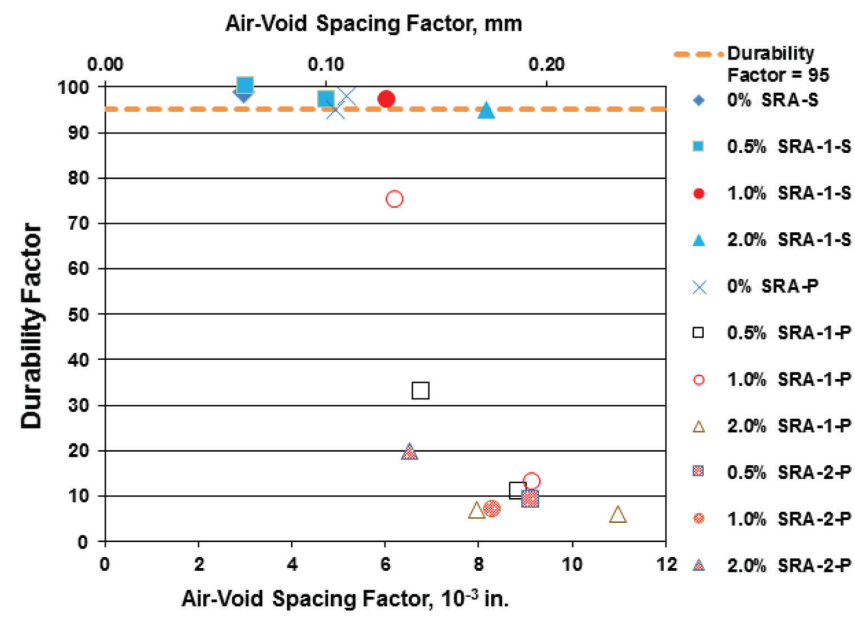

Fig. 7-Durability factor versus air-void spacing factor.

of the air-void system as the specimens were placed and consolidated. The mixtures with pAEA and SRA dosages of 0.5 and $1.0 \%$ experienced greater losses in air content than the corresponding mixtures with sAEA. For the mixtures with an SRA-1 dosage of $0.5 \%$ by weight of cement, the air content decreased from $8.5 \%$ in the plastic concrete to $7.9 \%$ in the hardened concrete for the sAEA mixtures (a $7.4 \%$ relative decrease), but from 8.5 to $6.0 \%$ for the pAEA mixtures (a 29.4\% relative decrease); for the single mixture with an SRA-2 dosage of $0.5 \%$ (with pAEA), air content decreased from 8.5 to $5.45 \%$ (a $35.8 \%$ relative decrease). For the mixtures containing a $1.0 \%$ dosage of SRA-1, the air content decreased from $8.3 \%$ in the plastic concrete to $6.4 \%$ in the hardened concrete for the sAEA mixtures (a $22.1 \%$ relative decrease), and from 7.8 to $5.9 \%$ for the pAEA mixtures (a $23.5 \%$ relative decrease); the values for the mixtures containing SRA-2 are 9.0 to $8.7 \%$ for the sAEA mixtures and 7.5 to 5.7 for the pAEA mixture (relative decreases of 3.3 and $24.0 \%$, respectively). Both sAEA and pAEA mixtures generally experienced greater losses in air content from the plastic to the hardened concrete as the dosage of SRA increased. The greatest losses in air content for the sAEA and pAEA mixtures occurred for the $2.0 \%$ dosage of SRA-1, with relative decreases in air content of 37.6 and $35.8 \%$, respectively, from the plastic to hardened

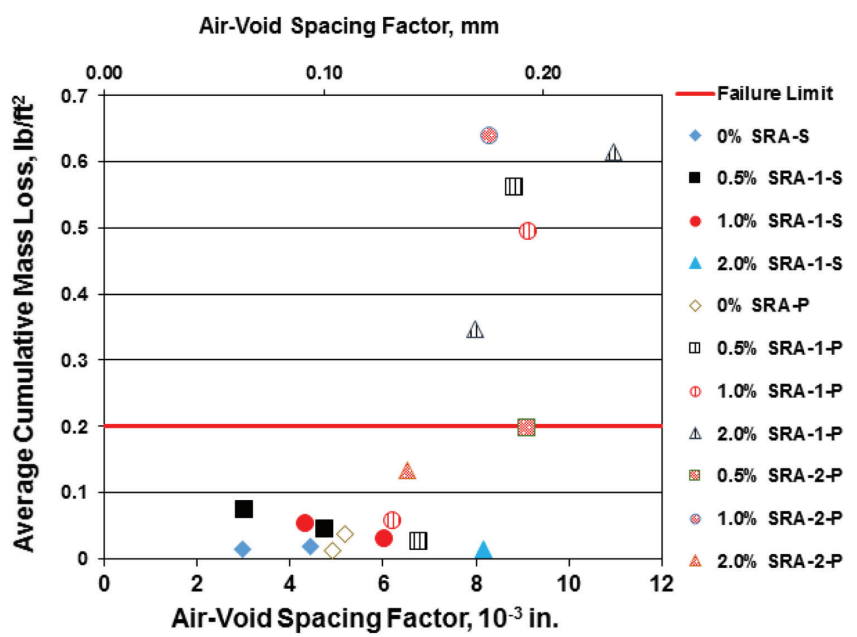

Fig. 8-Average cumulative mass loss due to scaling at 56 freezing-and-thawing cycles versus air-void spacing factor. (Note: $1 \mathrm{lb} / \mathrm{ft}^{2}=4.88 \mathrm{~kg} / \mathrm{m}^{2}$.)

condition compared to relative decreases of 17.2 and $25.1 \%$ for the SRA-2 mixtures.

To study the effect of SRA dosage on air-void spacing factors, the correlation between the dosages of SRA and air-void spacing factors is shown in Table 5 and Fig. 6 (the latter for SRA-1 only). As shown in the table and figure, the air-void spacing factor generally increased as the SRA-1 dosage increased for both the sAEA and pAEA mixtures. The spacing factor, however, is consistently lower for the sAEA mixtures than for the pAEA mixtures, even for those with no SRA. The highest air-void spacing factors correspond with the highest dosage of SRA-1 (2.0\%). In fact, the air-void spacing factors for both the SAEA and pAEA mixtures containing a dosage of $2.0 \%$ SRA-1 exceed 0.008 in. $(0.20 \mathrm{~mm})$. The largest difference in air-void spacing factor occurs in the mixtures containing $0.5 \%$ SRA-1, for which the sAEA and pAEA mixtures have average spacing factors of 0.004 and 0.008 in. (0.10 and $0.20 \mathrm{~mm})$, respectively. The spacing factor for each pAEA mixture with SRA-1 approaches or exceeds 0.008 in. $(0.20 \mathrm{~mm})$, even though each of these mixtures had a plastic air content of at least $7.5 \%$. The SRA-2 mixtures had a smaller sample size. The three SRA-2 mixtures containing pAEA had spacing factors between 0.009 and $0.007 \mathrm{in}$. $(0.23$ and $0.17 \mathrm{~mm})$, values that decreased as the SRA dosage increased. In contrast, the two SRA-2 mixtures containing sAEA had spacing factors below $0.004 \mathrm{in} .(0.10 \mathrm{~mm})$, the lowest in the study.

The durability factors (DF) in the freezing-and-thawing tests and the average cumulative mass loss after 56 freezingand-thawing cycles in scaling resistance tests are shown as functions of the average air-void spacing factors in Fig. 7 and Fig. 8, respectively. Lines representing a DF of 95 and a mass loss limit of $0.20 \mathrm{lb} / \mathrm{ft}^{2}\left(1000 \mathrm{~g} / \mathrm{m}^{2}\right)$ are shown in Fig. 7 and Fig. 8, respectively, to display the limits for acceptable freezing-and-thawing durability and scaling resistance. Air-void spacing factors, DFs, and values of mass loss after 56 freezing-and-thawing cycles are also shown in Table 6. Four of the 20 mixtures subjected to the hardened concrete air-void analyses (0\% SRA-S \#1, 1.0\% SRA-1-S \#1, 1.0\% SRA-2-S \#2, and 2.0\% SRA-2-S \#1) were not subjected to 
Table 6-Air-void spacing factor versus durability factor and mass loss after 56 freezing-andthawing cycles

\begin{tabular}{l|c|c|c|c}
\hline \multirow{2}{*}{ Mixture } & \multicolumn{2}{|c|}{$\begin{array}{c}\text { Air-void spacing } \\
\text { factor }\end{array}$} & Durability & $\begin{array}{c}\text { Cumulative mass } \\
\text { loss @ 56 cycles, } \\
\text { lb/ft }\end{array}$ \\
\cline { 2 - 5 } & in. & $\mathrm{mm}$ & factor & 0.019 \\
\hline $0 \%$ SRA-S \#1 & 0.0044 & 0.11 & $*$ & 0.014 \\
\hline $0.5 \%$ SRA-S \#3 & 0.0030 & 0.08 & 99 & 0.044 \\
\hline $0.5 \%$ SRA-1-S \#2 & 0.0048 & 0.12 & 97 & 0.072 \\
\hline $1.0 \%$ SRA-1-S \#1 & 0.0043 & 0.11 & $*$ & 0.052 \\
\hline $1.0 \%$ SRA-1-S \#2 & 0.0060 & 0.15 & 97 & 0.028 \\
\hline $2.0 \%$ SRA-1-S \#2 & 0.0082 & 0.21 & 95 & 0.015 \\
\hline $1.0 \%$ SRA-2-S \#2 & 0.0032 & 0.08 & $*$ & $*$ \\
\hline $2.0 \%$ SRA-2-S \#1 & 0.0037 & 0.09 & $*$ & $*$ \\
\hline $0 \%$ SRA-P \#1 & 0.0049 & 0.12 & 95 & 0.011 \\
\hline $0 \%$ SRA-P \#2 & 0.0052 & 0.13 & 98 & 0.037 \\
\hline $0.5 \%$ SRA-1-P \#1 & 0.0068 & 0.17 & 33 & 0.026 \\
\hline $0.5 \%$ SRA-1-P \#2 & 0.0089 & 0.22 & 11 & $0.561^{\dagger}$ \\
\hline $1.0 \%$ SRA-1-P \#1 & 0.0092 & 0.23 & 13 & 0.493 \\
\hline $1.0 \%$ SRA-1-P \#2 & 0.0062 & 0.16 & 75 & 0.056 \\
\hline $2.0 \%$ SRA-1-P \#1 & 0.0080 & 0.20 & 7 & 0.346 \\
\hline $2.0 \%$ SRA-1-P \#2 & 0.0110 & 0.28 & 6 & 0.615 \\
\hline $0.5 \%$ SRA-2-P \#1 & 0.0091 & 0.23 & 9 & 0.196 \\
\hline $1.0 \%$ SRA-2-P \#1 & 0.0083 & 0.21 & 7 & 0.637 \\
\hline $2.0 \%$ SRA-2-P \#1 & 0.0065 & 0.17 & 20 & 0.133 \\
\hline
\end{tabular}

*Mixture not tested.

TTest terminated after 35 cycles.

Note: $1 \mathrm{lb} / \mathrm{ft}^{2}=4.88 \mathrm{~kg} / \mathrm{m}^{2}$.

freezing-and-thawing testing; thus, durability factors for these specimens are not included in Table 6 and Fig. 7. In addition, two of these mixtures (1.0\% SRA-2-S \#2 and 2.0\% SRA-2-S \#1) were not tested for scaling resistance, and mass loss values for these specimens are not included in Table 6 and Fig. 8.

A clear relationship can be established between an increased air-void spacing factor and decreased freezingand-thawing durability and scaling resistance-a relationship that is consistent with the findings from previous studies. As shown in Fig. 7, six of the seven mixtures with a DF of 95 or greater had an air-void spacing factor less than or equal to 0.006 in. $(0.15 \mathrm{~mm})$. The seventh mixture, with a DF of 95 , had a spacing factor of 0.008 in. $(0.20 \mathrm{~mm})$, equal to the suggested limit for adequate freezing-and-thawing durability. However, four mixtures (1.0\% SRA-1-P \#2, 0.5\% SRA-1-P \#1, 2.0\% SRA-2-P \#1, and 2.0\% SRA-1-P \#1), all containing pAEA and an SRA with spacing factors between 0.006 and 0.008 in. ( 0.15 and $0.20 \mathrm{~mm})$, had DFs between 7 and 75 . The two mixtures with the highest DFs ( $0 \%$ SRA-S \#3 and $0.5 \%$ SRA-S \#2) had the lowest spacing factors. Conversely, the six mixtures with DFs below 20 each had a spacing factor greater than or equal to $0.008 \mathrm{in}$. $(0.20 \mathrm{~mm})$.
Scaling loss increased significantly as the air-void spacing factor approached or exceeded 0.008 in. $(0.20 \mathrm{~mm})$. Five of the seven mixtures with spacing factors equal to or greater than 0.008 in. $(0.20 \mathrm{~mm})(0.5 \%$ SRA-1-P \#2, $1.0 \%$ SRA-1-P \#1, 2.0\% SRA-1-P \#1, 2.0\% SRA-1-P \#2, and $1.0 \%$ SRA-2-P \#1), again all containing pAEA and an SRA, experienced scaling losses above the failure limit of $0.20 \mathrm{lb} / \mathrm{ft}^{2}\left(1000 \mathrm{~g} / \mathrm{m}^{2}\right)$ specified in BNQ NQ 2621900. Two mixtures with spacing factors above 0.008 in. $(0.20 \mathrm{~mm})(2.0 \%$ SRA-1-S \#2 and 0.5\% SRA-2-P \#1, with spacing factors of 0.0082 and 0.0091 , respectively), however, exhibited scaling losses of 0.01 and $0.19 \mathrm{lb} / \mathrm{ft}^{2}$ (50 and 975 $\mathrm{g} / \mathrm{m}^{2}$ ), respectively - one well below the limit and one just under the limit. The four mixtures with no SRA ( $0 \%$ SRA-S \#1, 0\% SRA-S \#3, 0\% SRA-P \#1, and 0\% SRA-P \#2) had spacing factors of $0.0052 \mathrm{in}$. $(0.13 \mathrm{~mm})$ or less and exhibited low mass losses. Nine out of 10 mixtures with spacing factors of 0.0065 in. $(0.17 \mathrm{~mm})$ or below exhibited scaling losses below $0.10 \mathrm{lb} / \mathrm{ft}^{2}\left(488 \mathrm{~g} / \mathrm{m}^{2}\right)$, one-half the failure limit.

\section{SUMMARY AND CONCLUSIONS}

The compatibility of two shrinkage-reducing admixtures (SRAs) with two air-entraining admixtures (AEAs) - one surfactant-based and one foaming polymer-based-was examined based on the freezing-and-thawing durability, scaling resistance, and air-void characteristics of hardened concrete. Twenty-four concrete mixtures containing dosages of $0,0.5,1.0$, and $2.0 \%$ by weight of cement of the two shrinkage-reducing admixtures were examined.

The following conclusions are based on the materials, test results, and analyses described in this paper.

1. When an SRA was not included, concretes containing either the surfactant-based or the foaming polymer-based AEA exhibited good freezing-and-thawing durability and scaling resistance.

2. When an SRA was used, concretes containing the surfactant-based AEA exhibited good freezing-and-thawing durability and scaling resistance, while those containing the foaming polymer-based AEA did not.

3. Both surfactant-based and polymer-based AEA mixtures containing an SRA experienced greater losses in air content from the plastic to the hardened concrete than those without an SRA, with losses increasing as the SRA dosage increased.

4. Increased dosages of SRA were associated with increased air-void spacing factors for both surfactant-based and polymer-based AEA mixtures.

5. The air-void spacing factors of the polymer-based AEA mixtures were consistently greater than those of the surfactant-based AEA mixtures, even for the mixtures with no SRA.

6. The mixtures with an increased air-void spacing factor experienced decreased freezing-and-thawing durability and scaling resistance, with the greatest effect for mixtures with air-void spacing factors above $0.008 \mathrm{in} .(0.20 \mathrm{~mm})$.

7. Ultimately, the polymer-based AEA did not, as originally expected, improve the stability of the air-void system when used in conjunction with an SRA. In fact, the polymerbased air-void system appeared to exhibit less stability than 
the surfactant-based system when an SRA was added to the concrete.

8. The differences in performance of the mixtures in this study emphasizes the importance of checking for admixture compatibility before application in the field.

\section{AUTHOR BIOS}

ACI member Benjamin Pendergrass is a Structural Engineer at Genesis Structures, Inc. He received his BA in physics from Drury University, Springfield, MO; his BS in civil and environmental engineering from the University of Missouri, Columbia, Columbia, MO; and his MS and PhD in civil engineering from the University of Kansas, Lawrence, KS.

ACI Honorary Member David Darwin is the Deane E. Ackers Distinguished Professor and Chair of the Department of Civil, Environmental, and Architectural Engineering at the University of Kansas, Lawrence, $K S$, and a Past President of ACI. He is a member of ACI Committees 222, Corrosion of Metals in Concrete; 224, Cracking; ACI Subcommittee 318-B, Anchorage and Reinforcement (Structural Concrete Building Code); and Joint ACI-ASCE Committees 408, Bond and Development of Steel Reinforcement; 445, Shear and Torsion; and 446, Fracture Mechanics of Concrete.

ACI member Muzai Feng is a Graduate Research Assistant at the University of Kansas. He received his MS in civil engineering from the University of Kansas.

ACI member Rouzbeh Khajehdehi is a Graduate Research Assistant at the University of Kansas. He received his MS in civil engineering from Southern Illinois University, Edwardsville, IL.

\section{ACKNOWLEDGMENTS}

Funding for this research was provided by the Kansas Department of Transportation (KDOT) serving as the lead agency for the "Construction of Crack-Free Bridge Decks, Phase II" Transportation Pooled Fund Study, Project No. TPF-5(174). The Federal Highway Administration of the U.S. Department of Transportation, the Departments of Transportation of Colorado, Indiana, Michigan, Minnesota, Mississippi, New Hampshire, New York, North Dakota, Ohio, Oklahoma, Texas, and Wisconsin, the Idaho Transportation Department, the University of Kansas Transportation Research Institute, BASF Construction Chemicals, and the Silica Fume Association provided funding to the pooled fund. Representatives from each sponsor served on a Technical Advisory Committee that provided advice and oversight to the project. Midwest Concrete Materials; Geiger Ready Mix; Ash Grove Cement; Lafarge North America; BASF Construction Chemicals; Miracon Technologies; Buildex, Inc.; Holcim, Inc.; and Euclid Chemical Company provided concrete materials. Hardened concrete air-void analysis was performed by the KDOT Materials Laboratory.

\section{REFERENCES}

ACI Committee 201, 2008, "Guide to Durable Concrete (ACI 201.2R-08)," American Concrete Institute, Farmington Hills, MI, 49 pp.

Bedard, C., and Mailvaganam, N., 2006, "The Use of Chemical Admixtures in Concrete. Part II: Admixture-Admixture Compatibility and Prac- tical Problems," Journal of Performance of Constructed Facilities, ASCE, V. 20, No. 1, pp. 2-5. doi: 10.1061/(ASCE)0887-3828(2006)20:1(2)

Bickley, J.; Hooten, R. D.; and Hover, K., 2006, "Preparation of a Performance-Based Specification for Cast-In-Place Concrete," RMC Research Foundation, Silver Spring, MD, pp. 3-14 to 3-18.

Darwin, D.; Browning, J.; and Lindquist, W. D., 2004, "Control of Cracking in Bridge Decks: Observations from the Field," Cement, Concrete and Aggregates, V. 26, No. 2, pp. 148-154.

Darwin, D.; Browning, J.; Lindquist, W.; McLeod, H. A. K.; Yuan, J.; Toledo, M.; and Reynolds, D., 2010, "Low-Cracking, High-Performance Concrete Bridge Decks-Case Studies Over the First 6 Years," Transportation Research Record: Journal of the Transportation Research Board, V. 2202, pp. 61-69. doi: 10.3141/2202-08

Darwin, D.; Browning, J.; McLeod, H. A. K.; Lindquist, W.; Yuan, J., 2012, "Implementing Lessons Learned From Twenty Years of Bridge-Deck Crack Surveys," Andy Scanlon Symposium on Serviceability and Safety of Concrete Structures: From Research to Practice, SP-284, American Concrete Institute, Farmington Hills, MI, pp. 8-1, 8-17.

Lindquist, W. D.; Darwin, D.; and Browning, J., 2008, "Development and Construction of Low-Cracking High-Performance Concrete (LC-HPC) Bridge Decks: Free Shrinkage, Mixture Optimization, and Concrete Production," SM Report No. 92, University of Kansas Center for Research, Lawrence, KS, 504 pp.

Lindquist, W. D.; Darwin, D.; Browning, J.; and Miller, G. G., 2006, "Effect of Cracking on Chloride Content in Concrete Bridge Decks," $A C I$ Materials Journal, V. 103, No. 6, Nov.-Dec., pp. 467-473.

Lopes, A. N.; Silva, E. F.; Dal Molin, D. C.; and Toledo Filho, R. D., 2013, "Shrinkage-Reducing Admixture: Effects on Durability of HighStrength Concrete," ACI Materials Journal, V. 110, No. 4, July-Aug., pp. 365-374.

McLeod, H. A. K.; Darwin, D.; and Browning, J., 2009, "Development and Construction of Low-Cracking High-Performance Concrete (LC-HPC) Bridge Decks: Construction Methods, Specifications, and Resistance to Chloride Ion Penetration," SM Report No. 94, University of Kansas Center for Research, Lawrence, KS, 815 pp.

McLeod, H. A. K.; Lindquist, W. D.; Browning, J.; and Darwin, D., 2010, "Effects of Construction Procedures and Material Properties on Low-Cracking High-Performance Concrete (LC-HPC) Bridge Decks," Proceedings, 2010 National Concrete Bridge Conference, Phoenix, AZ, $16 \mathrm{pp}$.

Mindess, S.; Young, F.; and Darwin, D., 2003, Concrete, second edition, Prentice-Hall, Englewood Cliffs, NJ, 644 pp.

Pendergrass, B., and Darwin, D., 2014, "Low-Cracking High-Performance Concrete (LC-HPC) Bridge Decks: Shrinkage-Reducing Admixtures, Internal Curing, and Cracking Performance," SM Report No. 107, the University of Kansas Center for Research, Lawrence, KS, 664 pp.

Powers, T. C., and Helmuth, R. A., 1953, "Theory of Volume Changes in Hardened Portland-Cement Paste during Freezing," Proceedings of the Annual Meeting - Highway Research Board, V. 32, pp. 285-297.

Verbeck, G. J., and Klieger, P., 1957, "Studies of 'Salt' Scaling of Concrete," Highway Research Board Bulletin, V. 150, pp. 1-13.

Yuan, J.; Darwin, D.; and Browning, J., 2011, "Development and Construction of Low-Cracking High-Performance Concrete (LC-HPC) Bridge Decks: Free Shrinkage Tests, Restrained Ring Tests, Construction Experience, and Crack Survey Results," SM Report No. 103, University of Kansas Center for Research, Lawrence, KS, 505 pp.

Yuan, J.; Lindquist, W.; Darwin, D.; and Browning, J., 2015, "Effect of Slag Cement on Drying Shrinkage of Concrete," ACI Materials Journal, V. 112, No. 2, Mar.-Apr., pp. 267-276. doi: 10.14359/51687129 